\title{
Pemodelan Sebaran Sedimen dan Analisis Kualitas Air di Muara Sungai Alindau, Donggala
}

\author{
Marwah, Yutdam Mudin, Elisa Sesa \\ Jurusan Fisika Fakultas Matematika dan Ilmu Pengetahuan Alam \\ Universitas Tadulako \\ email:marwahdemmmallehai@gmail.com
}

\begin{abstract}
ABSTRAK
Penelitian mengenai pemodelan sebaran sedimen dan analisis kualitas air telah dilakukan dengan obyek muara Sungai Alindau Kabupaten Donggala. Penelitian ini bertujuan memodelkan sebaran distribusi konsentrasi sedimen dan menganalisis kualitas air di muara Sungai Alindau yang dipengaruhi oleh aktivitas penambang pasir. Pemodelan ini menggunakan model numerik 2D dengan memanfaatkan data debit aliran sungai, data sedimen, data batimetri, dan gelombang pasang surut sebagai data inputnya. Luaran model menghasilkan pola arus serta pola sebaran sedimen di muara Sungai Alindau. Hasil penelitian menunjukan bahwa pola arus di perairan Sungai Alindau memiliki kecepatan arus maksimum terjadi pada saat kondisi pasang menuju surut purnama sebesar $0,023 \mathrm{~m} / \mathrm{s}$ dan kecepatan arus minimum terjadi pada kondisi pasang purnama sebesar $0,018 \mathrm{~m} / \mathrm{s}$. Secara keseluruhan sebaran sedimen melayang selama 29 hari di sekitar muara Sungai Alindau dominan ke arah barat laut dengan besar konsentrasi sedimen mencapai 0,306 gr/L. Hasil penentuan kualitas air di muara Sungai Alindau dengan melihat parameter BOD, COD, dan DO diperoleh bahwa BOD memiliki nilai 0 berada pada kategori kelas A (baik sekali) dengan status memenuhi Baku Mutu Lingkungan (BML), untuk hasil analisis COD memiliki nilai -12 masuk dalam kategori kelas C (Sedang) dengan status cemar sedang, sedangkan untuk parameter DO memiliki nilai -2 masuk ke dalam kategori kelas B (Baik) dengan status cemar ringan. Hasil simulasi modul SED2D untuk arah sebaran BOD dan COD adalah dominan ke arah barat laut.
\end{abstract}

Kata kunci : Kualitas air, Pola arus, Sebaran konsentrasi sedimen. 


\begin{abstract}
The research on sediment distribution modeling and water quality analysis has been carried out with the object of the Alindau River estuary in Donggala Regency. This study aims to model the distribution of sediment concentration distribution and analyze water quality at the Alindau River estuary which is influenced by the activity of sand miners. This modeling uses $2 \mathrm{D}$ numerical models using river flow, sediment discharge, bathymetry and tidal waves data as input. This output model produce current patterns and patterns of sediment distribution at the mouth of the Alindau River. The results showed that the current pattern in the waters of the Alindau River had a maximum current velocity that occurred when tide conditions towards full moon were 0,023 $\mathrm{m} / \mathrm{s}$ and the minimum current velocity occurred at full moon tide conditions of $0,018 \mathrm{~m} / \mathrm{s}$. Overall the distribution of sediments drifted for 29 days around the mouth of the Alindau River dominant to the northwest with large sediment concentrations reaching $0,306 \mathrm{gr} / \mathrm{L}$. The results of the determination of water quality at the Alindau River estuary based on BOD, COD, and DO data obtained that BOD is 0 in the category A (Very well) with the status fulfil environmental quality standards, to result of COD analyis has value -12 in the category class $\mathrm{C}$ (medium) with status moderate pollutant, while the DO parameter has value -2 in the category class B (well) with mild pollution status. Result of model SED2D simulation to direction of distribution of $\mathrm{BOD}$ and COD is dominant to the northwest.
\end{abstract}

Keywords: Water quality, Flow patterns, Sediment concentration distribution.

\section{PENDAhuluan}

Sedimentasi dapat terjadi karena adanya angkutan sedimen. Salah satu jenis angkutan sedimen adalah wash load yang terdiri dari partikel-partikel halus yang disebut sedimen tersuspensi atau sedimen melayang. Faktor yang dapat mempengaruhi sebaran distribusi sedimen melayang adalah arus, gelombang pasang surut, dan debit air (Soewarno, 1991).

Peristiwa sedimentasi bukan hanya terjadi di sungai tetapi juga terjadi di lingkungan pantai. Penyebab terjadinya sedimentasi di suatu lingkungan pantai disebabkan terdapatnya suplai muatan sedimen yang tinggi di tempat tersebut (Kumala, dkk., 2016). Salah satu faktor utama meningkatnya erosi di permukaan yang meningkatkan suplai muatan sedimen ke laut adalah adanya pembangunan di sekitar badan sungai serta adanya aktivitas masyarakat sehari-hari baik di sungai maupun di laut seperti mandi, mencuci, atau membuang sisa limbah rumah tangga ke tempat tersebut sehingga dapat mempengaruhi kualitas air (Pradiko dan Yulianti, 2010). Selain aktivitas masyarakat, hal lain yang juga dapat mempengaruhi kualitas air adalah adanya aktivitas penambangan pasir di badan sungai (Gulo, dkk., 2015).

Salah satu sungai yang menjadi lokasi penambangan pasir adalah Sungai Alindau. Sungai ini berada di Desa Alindau, Kecamatan Sindue, Kabupaten Donggala, Provinsi Sulawesi Tengah. Bahan galian yang ditambang di Sungai Alindau diantaranya 
adalah pasir, kerikil, dan batu kali. Selain menjadi lokasi penambangan, sungai ini juga dimanfaatkan oleh masyarakat untuk memenuhi kebutuhan air sehari-hari. Dengan adanya penambangan di sungai ini dapat menurunkan kualitas air yang dibutuhkan oleh masyarakat. Untuk mengetahui kualitas air di sungai ini maka perlu dilakukan penelitian.

Menurut Gulo, dkk (2015), dalam pengujiaan kualitas air Sungai Belawan Provinsi Sumatera Utara, diperoleh bahwa berdasarkan status mutu air sebelum adanya penambangan pasir, sungai tersebut berada pada kondisi baik (memenuhi standar baku mutu) akan tetapi setelah adanya penambangan pasir status dari sungai mengalami penurunan menjadi tercemar

Menurut Rizqan, dkk (2016), melakukan penelitian pada sekitar kawasan penambangan pasir di Sungai Batang Alai Kalimantan Selatan diketahui bahwa penurunan kualitas air dapat diuji dengan melihat beberapa nilai parameter pada status mutu air, dimana parameter-parameter tersebut diantaranya BOD (Biological Oxygen Demand), COD (Chemical Oxygen Demand), dan DO (Dissolve Oxygen).

Oleh karena itu, dengan melihat kondisi Sungai Alindau sekarang ini maka dianggap perlu untuk melakukan kajian mengenai sebaran sedimen dan analisis kualitas air di sungai tersebut dengan demikian diharapkan akan tersedia informasi mengenai dampak akibat aktivitas penambangan pasir di sekitar muara sungai tersebut dengan cara menganalisis parameter BOD, COD, dan DO. Selanjutnya melakukan simulasi pola sebaran sedimen dengan menggunakan Software SMS
(Surface Water Modelling System) modull RMA2 dan SED2D yang dibuat oleh Barbara P. Donnell pada Tahun 1996.

Menurut Barbara (2008), model RMA2 yang umum memecahkan persamaan kedalaman terintegrasi massa fluida dan konservasi momentum dalam dua arah horizontal. Bentuk-bentuk persamaan adalah:

$$
\begin{aligned}
& h \frac{\partial u}{\partial t}+h u \frac{\partial u}{\partial x}+h v \frac{\partial u}{\partial y}-\frac{h}{\rho}\left[E_{x x} \frac{\partial^{2} u}{\partial x^{2}}+\right. \\
& \left.E_{x y} \frac{\partial^{2} u}{\partial y^{2}}\right]+g h\left[\frac{\partial a}{\partial x}+\frac{a h}{a x}\right]+\frac{g u n^{2}}{\left(1.486 h^{\frac{1}{6}}\right)^{2}}\left(u^{2}+\right. \\
& \left.v^{2}\right)^{\frac{1}{2}}-\zeta V_{a}^{2} \cos \varphi-2 h \omega v \sin \phi=0
\end{aligned}
$$

$h \frac{\partial v}{\partial t}+h u \frac{\partial v}{\partial x}+h v \frac{\partial v}{\partial y}-\frac{h}{\rho}\left[E_{y x} \frac{\partial^{2} v}{\partial x^{2}}+\right.$

$\left.E_{y y} \frac{\partial^{2} u}{\partial y^{2}}\right]+g h\left[\frac{\partial a}{\partial y}+\frac{a h}{a y}\right]+\frac{g v n^{2}}{\left(1.486 h^{\frac{1}{6}}\right)^{2}}\left(u^{2}+\right.$

$\left.v^{2}\right)^{\frac{1}{2}}-\zeta V_{a}^{2} \cos \varphi-2 h \omega u \sin \phi=0$

$\frac{\partial h}{\partial t}+h\left(\frac{\partial u}{\partial x}+\frac{\partial v}{\partial y}\right)+u \frac{\partial h}{\partial x}+v \frac{\partial h}{\partial y}=0$

Analisa sedimentasi dilakukan dengan model SED2D. Persamaan Dasar pergerakan sedimen adalah Persamaan Konveksi-Diffusi (Barbara, 2009):

Persamaan Convection-diffusion

$\frac{\partial C}{\partial t}+u \frac{\partial C}{\partial x}+v \frac{\partial C}{\partial y}=\frac{\partial}{\partial x}\left(D_{x} \frac{\partial C}{\partial x}\right)+\frac{\partial}{\partial y}\left(D_{y} \frac{\partial C}{\partial y}\right)+$

$\alpha_{1} C+\alpha_{2}$ 


\section{METODE PENELITIAN}

\section{Lokasi Penelitian}

Penelitian dilakukan di muara Sungai Alindau Kabupaten Donggala. Sungai Alindau merupakan DAS (Daerah Aliran Sungai) yang memiliki lokasi penambangan pasir di sekitaran muara.

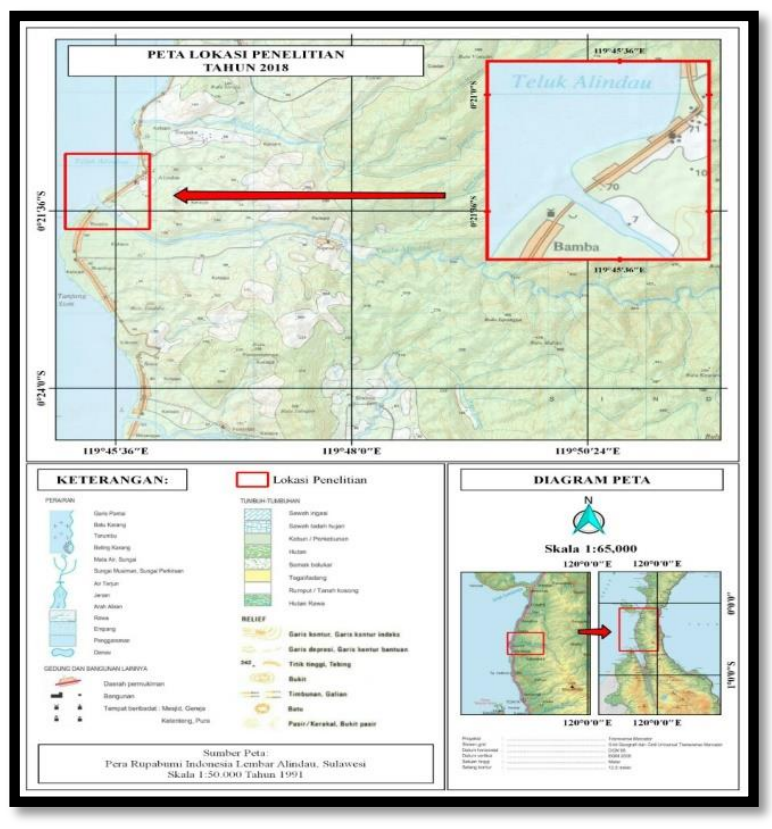

Gambar 1. Peta Lokasi Penelitian

\section{Pengambilan Data Primer}

Data primer meliputi data debit sungai, sedimen, dan data BOD, COD, DO. Data debit sungai diperoleh dengan cara menghitung luas penampang dan kecepatan arus sungai dengan menggunakan persamaan 5.

$Q=A \times V$

Data sedimen diperoleh dengan cara mengambil sampel air dengan menggunakan botol Nansen kemudian diuji di Laboratorium
Kimia FMIPA UNTAD untuk ditimbang dan dianalisis sehingga menghasilkan nilai konsentrasi sedimen dengan menggunakan persamaan 6 .

$\mathrm{C}_{\mathrm{s}}=\frac{\text { Msedimen }}{v}$

Data BOD, COD, dan DO diperoleh dengan cara membagi lokasi penelitian dengan menetapkan 3 stasiun pengukuran sampel. Stasiun sampel pertama berada tepat di tengah muara, stasiun sampel kedua berada di bagian sebelah kanan muara dengan jarak 100 meter dari stasiun sampel pertama, kemudian stasiun sampel ketiga berada di bagian kiri muara dengan jarak 100 meter dari sampel pertama. Sampel air diambil dengan menggunakan botol Nansen. Sampel air yang telah diperoleh di lapangan diuji di Laboratorium Kimia FMIPA UNTAD untuk dianalisis.

\section{Pengumpulan Data Sekunder}

Data sekunder yang dikumpulkan meliputi data-data penunjang penelitian seperti data gelombang pasang surut dan batimetri lokasi penelitian.

\section{Pengolahan Data Model}

Pengolahan data dilakukan menggunakan software SMS (Surface Water Modelling System) dengan modul RMA2 (Resources Management Associates-2) dan modul SED2D (Two Dimensional Sediment Transport Numerical Model) untuk memperoleh sebaran arus dan konsentrasi sedimen di lokasi penelitian. 


\section{Pengolahan Data BOD, COD, dan DO}

Status mutu perairan ditentukan dengan menggunakan Metode Storet berdasarkan Peraturan Pemerintah nomor 82 tahun 2001 tentang Pengolahan Kualitas Air dan Pengendalian Pencemaran Air. Metode ini membandingkan data kualitas air di lapangan dengan status baku mutu air yang disesuaikan dengan peruntukannya. Status mutu airnya ditentukan dari jumlah skor pada setiap parameter yang diamati. Apabila parameter yang diamati tidak melebihi baku mutu maka diberi skor nol. Berikut tabel penentuan status mutu air.

Tabel 1. Penentuan Sistem Nilai untuk Menentukan Status Mutu Air

\begin{tabular}{ccccc}
\hline \multirow{2}{*}{ No } & \multirow{2}{*}{ Nilai } & \multicolumn{3}{c}{ Parameter } \\
\cline { 3 - 5 } & & Fisika & Kimia & Biologi \\
\hline 1 & Maksimum & -1 & -2 & -3 \\
\hline 2 & Minimum & -1 & -2 & -3 \\
\hline 3 & Rata-rata & -3 & -6 & -9
\end{tabular}

Semua skor yang diperoleh berdasarkan parameter yang diuji kemudian dianalisis dan dijumlahkan. Berdasarkan jumlah yang telah diperoleh selanjutnya mengklasifikasikan mutu air tersebut ke dalam sistem nilai penentuan status mutu air.

Tabel 2. Sistem Nilai Penentuan Status Mutu Air

\begin{tabular}{cccc}
\hline No & Kategori & Skor & Status \\
\hline 1. & $\begin{array}{c}\text { Kelas A (Baik } \\
\text { Sekali) }\end{array}$ & 0 & $\begin{array}{c}\text { Memenuhi } \\
\text { BML }\end{array}$ \\
\hline 2. & Kelas B (Baik) & $-1 \mathrm{~s} / \mathrm{d}-10$ & Cemar Ringan \\
\hline 3. & $\begin{array}{c}\text { Kelas C } \\
\text { (Sedang) }\end{array}$ & $\begin{array}{c}-11 \mathrm{~s} / \mathrm{d}- \\
30\end{array}$ & Cemar Sedang \\
\hline 4. & Kelas D (Buruk) & $>-31$ & Cemar Berat \\
\hline
\end{tabular}

\section{HASIL DAN PEMBAHASAN}

1. Pola Arus

Berdasarkan hasil model hidrodinamika dengan menggunakan modul RMA2 di perairan Alindau diperoleh pola pergerakan arus yang dominan dipengaruhi oleh pasang surut. Tipe pasang surut di daerah ini adalah tipe condong harian ganda (mixed tide prevailing semidiurnal), tipe ini terjadi 2 kali air pasang dan 2 kali air surut dalam sehari. Arus yang dipengaruhi oleh pasang surut ditandai dengan ketika terjadi posisi pasang arus bergerak masuk ke arah muara, sedangkan ketika posisi surut arus bergerak meninggalkan muara ke arah laut lepas. Berikut adalah kecepatan arus serta pola arus yang terbentuk pada saat pasang surut purnama.

Tabel 3. Kecepatan arus di muaraSungai Alindau

\begin{tabular}{ccccc}
\hline \multirow{2}{*}{ Fase } & \multicolumn{4}{c}{ Kecepatan Arus Muara Sungai Alindau } \\
\cline { 2 - 5 } & Pasang & $\begin{array}{c}\text { Menuju } \\
\text { Surut }\end{array}$ & Surut & $\begin{array}{c}\text { Menuju } \\
\text { Pasang }\end{array}$ \\
\hline Purnama & 0,0186 & 0,023 & 0,0195 & 0.0203 \\
\hline
\end{tabular}

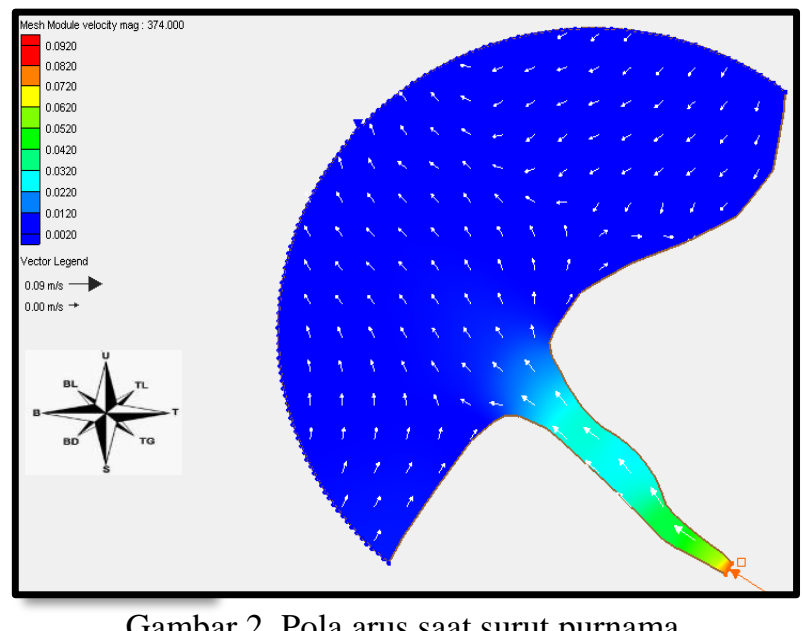

Gambar 2. Pola arus saat surut purnama 


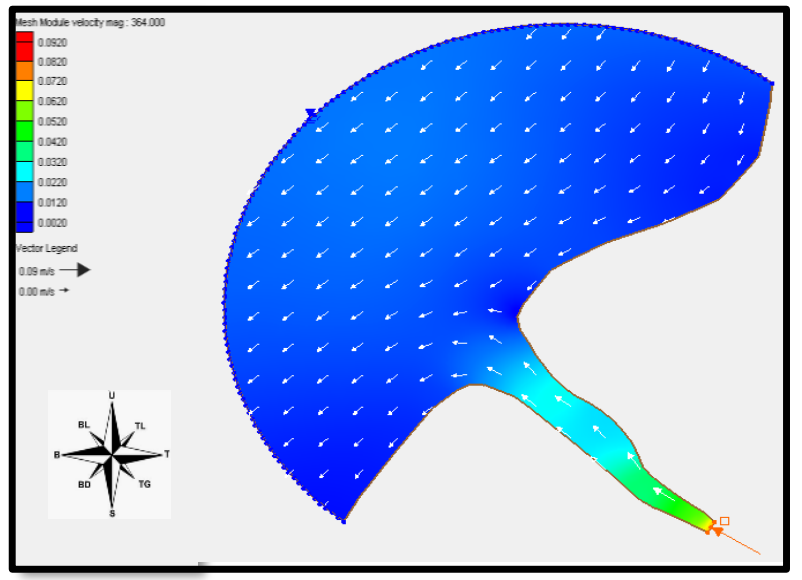

Gambar 3. Pola arus saat surut menuju pasang purnama



Gambar 4. Pola arus saat pasang purnama

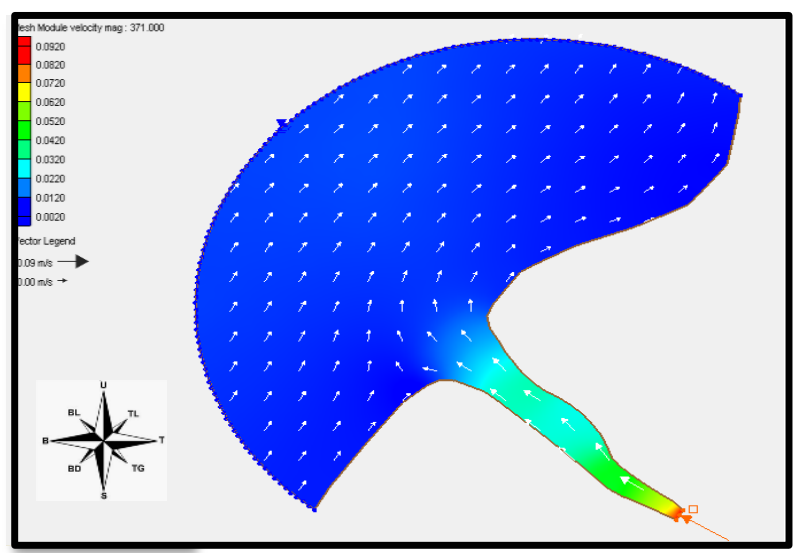

Gambar 5. Pola arus saat pasang menuju surut purnama

\section{Sebaran Konsentrasi Sedimen}

Berdasarkan hasil simulasi modul SED2D untuk sebaran konsentrasi sedimen melayang selama 29 hari dengan masukan konsentrasi sedimen sebesar 0,306 gr/. Diperoleh arah sebaran yang dominan menuju ke arah barat laut dengan besar konsentrasi sedimen 0,209 $\mathrm{gr} / \mathrm{L}-0,299 \mathrm{gr} / \mathrm{L}$. Pada bagian sungai memiliki nilai konsentrasi sedimen yang paling besar sedangkan pada bagian muara sungai nilai konsentrasi sedimen mulai menurun



Gambar 6. Model sebaran konsentrasi sedimen 
3. Analisis BOD, COD, dan DO

Tabel 4. Penentuan Kualitas Air di Muara Alindau Kabupaten Donggala

\begin{tabular}{ccccccccccc}
\hline \multirow{2}{*}{ No } & Parameter & \multicolumn{9}{c}{ Hasil Analisa } \\
\cline { 2 - 11 } & & St 1 & St 2 & St 3 & Max & Min & Rata-rata & Nilai & Satuan \\
\hline 1 & BOD & 1,150 & 0,433 & 0.400 & 1,150 & 0,433 & 0,661 & 6 & $\mathrm{mg} / \mathrm{L}$ \\
\hline 2 & COD & 50,500 & 75 & 26,333 & 75 & 26,333 & 50,611 & 50 & $\mathrm{mg} / \mathrm{L}$ \\
\hline 3 & DO & 3,600 & 1,033 & 0,633 & 3,600 & 0,633 & 1,755 & $>3$ & $\mathrm{mg} / \mathrm{L}$ \\
\hline
\end{tabular}

(Sumber Baku Mutu: Peraturan pemerintah nomor 82 tahun 2001)

Berdasarkan hasil penentuan kualitas air di muara Sungai Alindau pada stasiun 1,2, dan 3 diperoleh hasil seperti pada Tabel 4. Hasil pada setiap stasiun tersebut di masukkan ke dalam Tabel 1 untuk penentuan sistem nilai status mutu air. Hasil penentuan tersebut dapat dilihat pada Tabel 5.

Tabel 5. Hasil Skoring Metode STORED untuk Menentukan Status Mutu Air di Lokasi Penelitian

\begin{tabular}{|c|c|c|c|c|}
\hline \multirow{2}{*}{ No } & \multirow{2}{*}{ Lokasi } & \multicolumn{3}{|c|}{ Skore Parameter } \\
\cline { 3 - 5 } & & BOD & COD & DO \\
\hline 1 & Stasiun 1 & 0 & -2 & 0 \\
\hline 2 & Stasiun 2 & 0 & -10 & 0 \\
\hline 3 & Stasiun 3 & 0 & 0 & -2 \\
\hline \multicolumn{2}{|c|}{ Total Skore } & 0 & -12 & -2 \\
\hline
\end{tabular}

BOD

Pada Tabel 4 dapat dilihat pada stasiun 1, 2, dan 3 memiliki nilai BOD yang masih di bawah standar baku mutu dengan nilai minimum $0,433 \mathrm{mg} / \mathrm{L}$ dan nilai maksimum 1,150 mg/L. Berdasarkan Tabel 5 untuk hasil analisis BOD di muara Sungai Alindau dengan menggunakan metode storet diperoleh skor 0. Maka status Sungai Alindau berdasarkan Tabel 2 berada pada kategori kelas A dengan status memenuhi Baku Mutu Lingkungan (BML).

\section{COD}

Berdasarkan Tabel 4 nilai COD tertinggi berada pada stasiun 2 yaitu $75 \mathrm{mg} / \mathrm{L}$, kemudian stasiun 1 yaitu $50,500 \mathrm{mg} / \mathrm{L}$, dan stasiun 3 sebesar 26,333 mg/L. Hasil analisis COD untuk stasiun 1, 2, dan 3 menunjukkan bahwa pada stasiun 1 dan 2 memiliki nilai COD yang melebihi ambang baku mutu sedangkan pada stasiun 3 nilai COD masih di bawah baku mutu. Maka berdasakan Tabel 5 COD memiliki skor -12 dan berada pada kategori kelas C (sedang) dengan status Cemar Sedang. Status tersebut dapat dilihat pada Tabel 2. Meningkatnya nilai COD di Sungai Alindau dengan status cemar sedang akan berpengaruh terhadap kualitas air yang digunakan oleh masyarakat untuk kebutuhan sehari-hari karena memiliki senyawa kimia yang melebihi baku mutu yang telah ditetapkan. Apabila kondisi sungai meningkat hingga mencapai status cemar berat maka air sungai tersebut berbahaya apabila digunakan oleh masyarakat untuk kebutuhan sehari-hari. 


\section{DO}

Hasil analisis DO pada stasiun 1, 2, dan 3, mengalami penurunan pada stasiun 2 dan 3 sedangkan pada stasiun 1 tepatnya di tengah muara DO masih berada di dalam ambang baku mutu. Pada Stasiun 3 memiliki nilai DO yang paling rendah yaitu $0,633 \mathrm{mg} / \mathrm{L}$, Stasiun 2 nilai DO sebesar $1,033 \mathrm{mg} / \mathrm{L}$, sedangkan pada stasiun 1 nilai DO yaitu 3,600. Dapat dilihat pada Tabel 5 DO memiliki skor -2 sehingga berdasarkan Tabel 2 muara Sungai Alindau berada pada kategori kelas B (baik) dengan status Cemar Ringan.

\section{Model Sebaran BOD dan COD}

Model keluaran sebaran BOD dan COD memeliki masukan (input) yang sama yaitu gelombang pasang surut dan debit air. Model ini juga menggunakan mesh yang sama pada model arus dan konsentrasi sedimen melayang dengan waktu simulasi selama 29 hari (696 jam). Bagian mulut sungai sampai batas terbuka sungai pada model memiliki jarak yang sama sebesar $1 \mathrm{~km}$ sedangkan untuk jarak dari mulut sungai sampai ke batas terbuka laut adalah $863 \mathrm{~m}$. berikut adalah model sebaran BOD dan COD:

\section{Biological Oxygen Demand (BOD)}

Berdasarkan hasil simulasi model numerik 2D sebaran BOD selama 29 hari (696 Jam) di Sungai Alindau, dapat dilihat pada Gambar 7 dimana besar nilai BOD yang menjadi masukan adalah 0,661 mg/L. Nilai BOD tertinggi berada pada daerah sungai dan mulai mengecil saat menuju mulut sungai. Sebaran BOD di Sungai Alindau masih dalam keadaan normal atau memenuhi standar baku mutu sebesar $6 \mathrm{mg} / \mathrm{L}$.



Gambar 7 Model sebaran Biological Oxygen Demand (BOD)

\section{Chemical Oxygen Demand (COD)}

Berdasarkan Gambar 8 dimana besar nilai COD yang menjadi masukan adalah 50,611 $\mathrm{mg} / \mathrm{L}$. Sebaran nilai COD tertinggi berada pada bagian batas terbuka sungai dan mulai mengecil saat menuju mulut sungai. Nilai COD di bagian batas terbuka Sungai Alindau sebesar 50,300 $\mathrm{mg} / \mathrm{L}$ maka telah melewati standar baku mutu yaitu $50 \mathrm{mg} / \mathrm{L}$ sehingga mengakibatkan turunnya kualitas air di daerah tersebut. Pada bagian muara sungai nilai COD kembali normal sebesar $35 \mathrm{mg} / \mathrm{L}$ atau berada dalam standar baku mutu. 


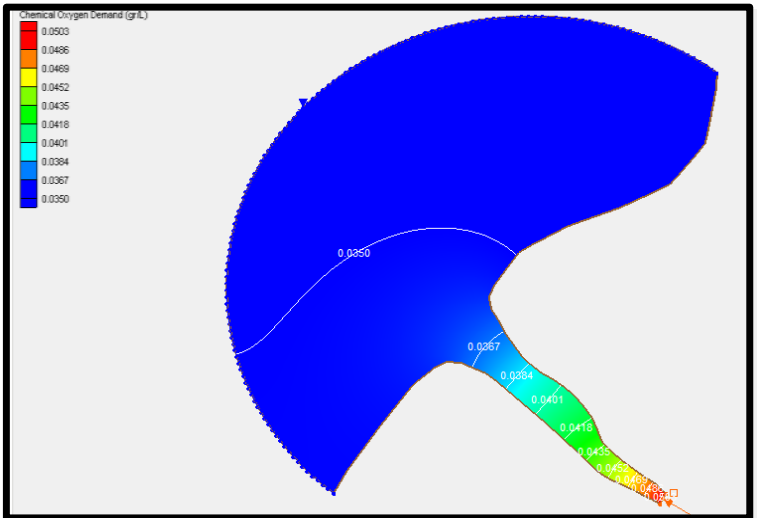

Gambar 8 Model sebaran Chemical Oxygen Demand (COD)

\section{KESIMPULAN}

Berdasarkan hasil analisis model SMS 8.1 dengan modul SED2D sebaran konsentrasi sedimen melayang yang dihasilkan selama 29 hari (696 jam) dengan masukan konsentrasi sedimen sebesar 0,306 gr/L, diperoleh konsentrasi sedimen melayang di bagian laut sebesar 0,209 gr/L dan mengalami peningkatan pada bagian mulut Sungai Alindau sebesar 0,219 gr/L. Arah sebaran dominan ke arah barat laut. Meningkatnya konsentrasi sedimen melayang dapat mempengaruhi kualitas air. Berdasarkan nilai BOD di muara Sungai Alinda berada pada kategori kelas A (baik sekali) dengan skor 0 yang berarti masih memenuhi Baku Mutu Lingkungan (BML). Untuk nilai COD berada pada kategori kelas $\mathrm{C}$ (sedang) dengan skor 12 berada pada kondisi cemar sedang. Sedangkan untuk parameter DO masuk dalam kategori kelas B (baik) dengan skor -2 yang berada pada kondisi cemar ringan. Arah sebaran BOD dan COD dominan ke arah barat laut.

\section{DAFTAR PUSTAKA}

Barbara, P. (2008). User Guide To RMA2 Version 4.5, US Army. Engineer Research and Development Center Waterways Experiment Station Coastal and Hydraulics Laboratory, USA.

Barbara, P. (2009). User Guide To SED2D Wes Version 4.5, US Army. Engineer Research and Development Center Waterways Experiment Station Coastal and Hydraulics Laboratory, USA.

Gulo, U., Z., Barus, T, A., Suryanti, A. (2015). Kualitas Air Sungai Belawan Kecamatan Pancur Batu Kabupaten Deli Serdang Provinsi Sumatera Utara. Medan: Universitas Sumatra Utara.

Kumala, G, F., Hamdhani., dan Jailani. (2016). Pengaruh hidrodinamika pasar laut terhadap material sedimen diperairan muara Sembilang Kecamatan Samboja Kabupaten Kutai Kartanegara. Jurnal ilmu perikanan tropis, 21(2), 9-17.

Pradiko, H., dan Yulianti , P. (2010). Analisis kualitas air dan sedimen di daerah muara sungai cipalabuhan. Jurnal Teknik Lingkungan, 4(1), 209-220.

Rizqan A, Idianor Mahyudin, Mijani Rahman, Jamsuri Hadie. (2016). Status Kualitas Air Sungai Sekitar Kawasan Penambangan Pasir Di Sungai Batang Alai Desa Wawai Kalimantan Selatan. Banjarmasin: Universitas Lambung Mangkurat.

Soewarno. (1991). Hidrologi Pengukuran dan Pengolahan Data Aliran Sungai (Hidrometri). Bandung: Nova. 